\title{
Blood Pressure Effects of High-Dose Amlodipine-Benazepril Combination in Black and White Hypertensive Patients Not Controlled on Monotherapy
}

\author{
Steven G. Chrysant
}

Oklahoma Cardiovascular and Hypertension Center and University of Oklahoma Health and Sciences Center, Oklahoma City, OK, USA

Background: Black hypertensive patients are more resistant to angiotensinconverting enzyme (ACE) inhibitor monotherapy than White patients. This resistance can be overcome with the combination of ACE inhibitors with diuretics or calcium-channel blockers (CCBs).

Objectives: The objective of this clinical investigation was to evaluate the antihypertensive effectiveness of monotherapy with the ACE inhibitor benazepril or the CCB amlodipine and their combination in Black and White hypertensive patients in two separate studies.

Methods: This was a post hoc analysis of data from two separate studies, pooled because of their similarities, to increase the sample size. Outpatient Black and White hypertensive patients were selected for these studies. In study H2303, 201 patients of both sexes and races, whose mean seated diastolic blood pressure (MSDBP) was $\geq 95 \mathrm{mmHg}$ after 4 weeks of single-blind treatment with benazepril $40 \mathrm{mg} /$ day, were randomized into two groups. Group 1 received benazepril $40 \mathrm{mg} /$ day and group 2 received amlodipine/ benazepril $5 / 40 \mathrm{mg} /$ day, which was uptitrated to amlodipine/benazepril $10 / 40 \mathrm{mg} /$ day at week 4 of the study. In study H2304, 812 similar patients, whose MSDBP was $\geq 95 \mathrm{mmHg}$ after 4 weeks of single-blind treatment with amlodipine $10 \mathrm{mg} / \mathrm{day}$, were randomized into three groups. Group 1 received amlodipine/benazepril $10 / 20 \mathrm{mg} /$ day, uptitrated to amlodipine/benazepril 10/40 mg/day after 2 weeks. Group 2 received amlodipine/benazepril 10/20 mg/day. Group 3 received amlodipine $10 \mathrm{mg} /$ day. All three groups were followed up for 6 additional weeks.

Results: This report presents the results of post hoc analysis of pooled data from two separate but similar studies. Combination therapy resulted in greater lowering of MSDBP and mean seated systolic blood pressure (MSSBP) than monotherapy with either benazepril or amlodipine $(\mathrm{p}<0.001)$. With respect to combination therapy, the combination of amlodipine/benazepril $10 / 20 \mathrm{mg}$ /day 
resulted in greater blood pressure (BP) reductions in White patients than in Black patients $(\mathrm{p}<0.004)$. In contrast, the combination of amlodipine/ benazepril 10/40 $\mathrm{mg} /$ day resulted in similar BP reductions in both Black and White hypertensive patients. There were no serious clinical or metabolic side effects noted, with the exception of pedal edema, which was more common with amlodipine monotherapy.

Conclusion: This study showed that combination therapy with amlodipine/ benazepril is more effective in BP lowering than monotherapy with the component drugs. Black hypertensive patients are responsive to the combination of amlodipine/benazepril; however, they require higher dose combinations for BP reductions similar to those achieved in White hypertensive patients.

\section{Introduction}

Blood pressure (BP) control rates are improving but are still far from adequate. The latest report stated that BP control has improved considerably from $25 \%$ to $50 \%$ at present. ${ }^{[1]}$ Although these control rates may be true for the recommended BP goals of $<140 / 90 \mathrm{mmHg}$ for uncomplicated hypertension, the control rates for the more aggressive goal of $<130 / 80 \mathrm{mmHg}$ for persons with diabetes mellitus, chronic renal disease, or coronary heart disease (CHD) are lower. ${ }^{[2-5]}$ Most studies show that in order to reach these goals, the majority of patients will require two or more antihypertensive drugs. ${ }^{[6-10]}$ Calcium-channel blockers (CCBs) and angiotensin-converting enzyme (ACE) inhibitors are still recommended for first-line therapy for hypertension, ${ }^{[2,3]}$ but given alone, do not produce BP reductions to currently recommended BP goals, and in most patients with stage 2 hypertension, a combination of two drugs from different classes is recommended. ${ }^{[2-4]}$ The combination of a CCB with an ACE inhibitor is particularly attractive for patients with diabetes or hyperlipidemia because both drugs are metabolically neutral. In addition, the combination of an ACE inhibitor with amlodipine, a dihydropyridine CCB, will increase the latter's antihypertensive effect ${ }^{[11-14]}$ and ameliorate the incidence and magnitude of pedal edema. ${ }^{[1,12]}$

The currently available fixed-dose combination of amlodipine/benazepril $5 / 10$ and $10 / 20$ $\mathrm{mg}$ /day has been effective in reducing $\mathrm{BP}$, but more aggressive treatment of hypertension with higher-dose combinations may be necessary to bring BP to goal, especially in populations like Black patients, who are resistant to treatment. ${ }^{[13]}$ Several clinical trials have shown that the combination of ACE inhibitors or angiotensin-receptor blockers (ARBs) with a CCB is synergistic and provides greater reductions of $\mathrm{BP}$ in a variety of hypertensive populations, and the vasodilatory edema seen with the dihydropyridine CCBs is usually decreased with their combination. ${ }^{[11,12,15-18]}$

In this report, we present the effectiveness and safety of a high-dose combination of benazepril with amlodipine in Black and White hypertensive patients compared with high-dose monotherapy with benazepril hydrochloride $40 \mathrm{mg} /$ day or amlodipine besylate $10 \mathrm{mg} /$ day.

\section{Subjects and Methods}

Study H2303 consisted of 291 completed subjects and study H2304 consisted of 763 completed subjects. All subjects were well matched for age and sex and other clinical parameters. Both studies were multi-center and double blinded. The schematic of both studies is depicted in figure 1. All participating sites had IRB approval and each subject signed an informed consent form before participating in the study.

In study $\mathrm{H} 2303$, after a 2-week drug washout period, all patients with a mean sitting diastolic BP (MSDBP) of $\geq 95 \mathrm{mmHg}$ and $<110 \mathrm{mmHg}$ entered a single-blind period of treatment with 
a

Study H2303

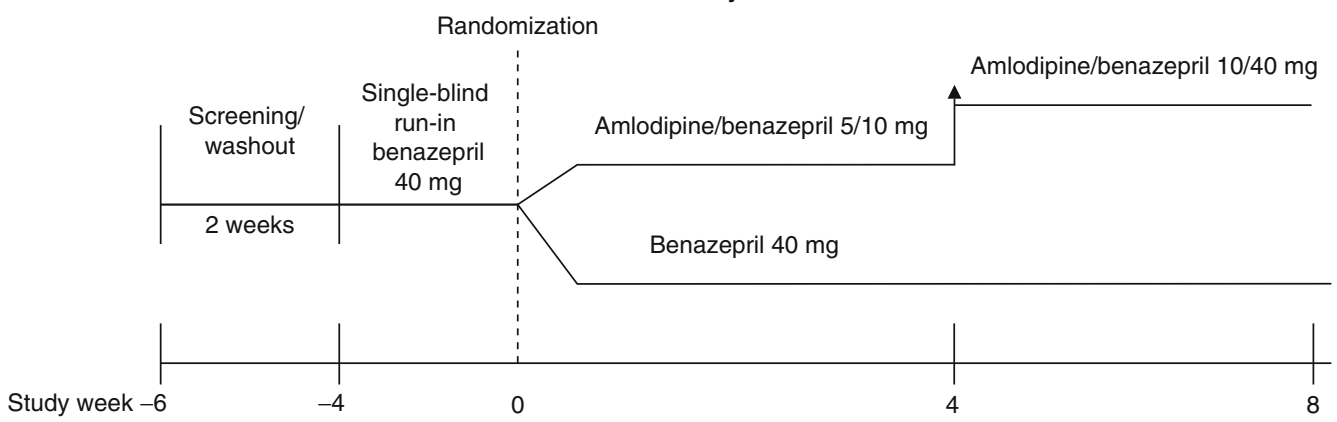

b

Study H2304

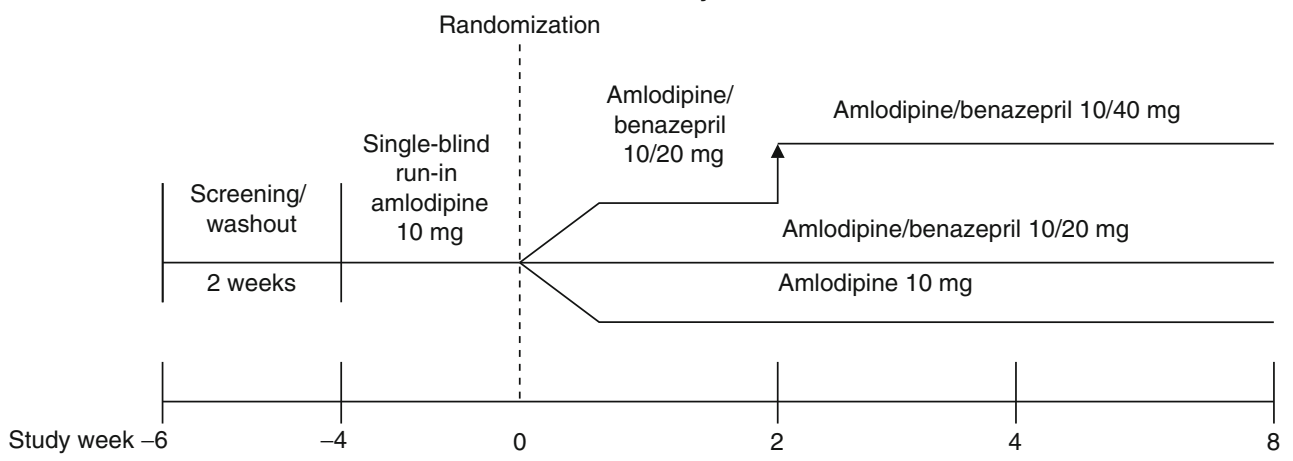

Fig. 1. Schematic designs of (a) study $\mathrm{H} 2303$ and (b) study $\mathrm{H} 2304$.

benazepril $40 \mathrm{mg} /$ day for 4 weeks. At the end of this period, those patients whose MSDBP was $\geq 95 \mathrm{mmHg}$ and $<110 \mathrm{mmHg}$ were equally randomized to combination therapy with benazepril $40 \mathrm{mg}$ plus amlodipine $5 \mathrm{mg}$ [amlodipine/benazepril $5 / 40 \mathrm{mg}$ ] per day for 4 weeks and then were forcetitrated to amlodipine/benazepril $10 / 40 \mathrm{mg} /$ day for an additional 4 weeks. The other patients continued on benazepril $40 \mathrm{mg} /$ day for 8 weeks.

In study $\mathrm{H} 2304$, the same study design was followed as in $\mathrm{H} 2303$, with the exception that the single-blind monotherapy period for 4 weeks consisted of amlodipine $10 \mathrm{mg} /$ day. At the end of 4 weeks, those patients whose MSDBP was $\geq 95 \mathrm{mmHg}$ and $<110 \mathrm{mmHg}$ were equally randomized into three groups. Group 1 was randomized to amlodipine/benazepril $10 / 20 \mathrm{mg} /$ day for 2 weeks and then force-titrated to amlodipine/benazepril $10 / 40 \mathrm{mg} /$ day for an additional 6 weeks. Group 2 was randomized to amlodipine/benazepril 10/20 $\mathrm{mg}$ /day for 8 weeks, and group 3 continued on amlodipine $10 \mathrm{mg} /$ day for 8 weeks. Patients with severe hypertension (MSDBP $\geq 115 \mathrm{mmHg}$ and mean seated systolic blood pressure [MSSBP] $\geq 180 \mathrm{mmHg}$ ) were excluded from participation in the studies. Also, females with childbearing potential were required to practice an effective method of contraception in order to participate in the studies and, in addition, patients with serious medical conditions were excluded from participation.

The sitting BP was measured at approximately $24 \pm 2$ hours after the previous dose of study medication in the office with a mercury sphygmomanometer after 5 minutes of sitting, in the same arm and by the same person, approximately $80 \%$ of the time. Three BP readings 2 minutes apart were taken, and the values were averaged. The safety of the drugs was assessed by close monitoring of all clinical and metabolic side effects. 
Table I. Baseline demographic characteristics at the end of monotherapy

\begin{tabular}{|c|c|c|c|c|}
\hline Characteristic & $\begin{array}{l}\text { Amlodipine/ } \\
\text { benazepril } \\
10 / 40 \mathrm{mg}\end{array}$ & $\begin{array}{l}\text { Amlodipine/ } \\
\text { benazepril } \\
\text { 10/20 mg }\end{array}$ & $\begin{array}{l}\text { Amlodipine } \\
10 \mathrm{mg}\end{array}$ & $\begin{array}{l}\text { Benazepril } \\
40 \mathrm{mg}\end{array}$ \\
\hline Patients (n [\%]) & 432 & 273 & 271 & 165 \\
\hline White & $272[63]$ & $169[62]$ & $168[62]$ & $99[60]$ \\
\hline Black & $108[25]$ & $71[26]$ & $73[27]$ & $46[28]$ \\
\hline Other minorities not included in the analysis & $52[12]$ & $33[12]$ & $30[11]$ & $20[12]$ \\
\hline Body mass index $\left(\mathrm{kg} / \mathrm{m}^{2}\right)^{\mathrm{a}}$ & 32 & 32 & 31 & 32 \\
\hline \multicolumn{5}{|l|}{ Blood pressure (mmHg; MMSBP/MSDBP)a } \\
\hline White & $146.5 / 98.8$ & $145.4 / 98.3$ & $144.3 / 97.7$ & $147.7 / 98.7$ \\
\hline Black & $149.2 / 99.4$ & $147.5 / 98.4$ & $145.7 / 98.8$ & $149.3 / 99.4$ \\
\hline
\end{tabular}

a Excluding data on other minorities not included in the analysis.

MSSBP $=$ mean seated systolic blood pressure; $\mathbf{M S D B P}=$ mean seated diastolic blood pressure .

\section{Statistical Analysis}

Because of the similarities of patients receiving amlodipine/benazepril 10/40 mg/day, the data from these patients in both studies were pooled to increase the sample size. The baseline demographics at the end of the baseline monotherapies are listed in table I. This table lists the baseline data by treatment group for both Black and White patients. The efficacy and safety of treatment regimens was performed by intent-to-treat (ITT) analysis. In this analysis, all patients who took at least one dose of randomized study medication and had a baseline and at least one post-randomization efficacy measurement were included. Changes in BP from baseline to endpoint were analyzed using two-way analysis of covariance models, with treatment and center as factors and baseline measurements as a covariate. Treatment-by-center interaction was also investigated. Within-treatment comparisons were analyzed using one-sample t-tests. All treatment comparisons were made at a two-sided significance level of 0.05 . The proportion of patients in each treatment group achieving a successful reduction in diastolic $\mathrm{BP}$ was compared using a logistic regression model with treatment and center as co-factors and the dichotomous response as the dependent variable.

\section{Results}

Continued monotherapy with benazepril $40 \mathrm{mg}$ /day after randomization to double-blind therapy reduced MSDBP from baseline by $7.1 \mathrm{mmHg}$ in White patients $(\mathrm{p}<0.0001)$ and by $4.77 \mathrm{mmHg}$ in Black patients $(\mathrm{p}<0.0002)$, and reduced MSSBP by $6.00 \mathrm{mmHg}$ in White patients $(p<0.0001)$ and by $1.85 \mathrm{mmHg}$ in Black patients ( $p$-value not significant). The difference in MSDBP was not significant between Black and White patients, but the difference in MSSBP was significant $(\mathrm{p}<0.05)$.

Continued monotherapy with amlodipine $10 \mathrm{mg}$ /day decreased MSDBP from baseline by $9.2 \mathrm{mmHg}$ in White patients and by $8.9 \mathrm{mmHg}$ in Black patients $(\mathrm{p}<0.001)$, and reduced MSSBP by $5.8 \mathrm{mmHg}$ in White patients and by $9.4 \mathrm{mmHg}$ in Black patients $(\mathrm{p}<0.001$ for both). There was no difference in the reductions of MSDBP and MSSBP between the two groups. The combination treatment of amlodipine/benazepril 10/20 mg/day decreased MSDBP from baseline by $12.99 \mathrm{mmHg}$ in White patients $(\mathrm{p}<0.0001)$ and by $8.80 \mathrm{mmHg}$ in Black patients $(\mathrm{p}<0.0001)$, and decreased MSSBP by $13.72 \mathrm{mmHg}$ in White patients $(\mathrm{p}<0.0001)$ and by $8.72 \mathrm{mmHg}$ in Black patients $(\mathrm{p}<0.0001)$. This drug combination resulted in significantly greater BP reductions in White patients than in Black patients $(\mathrm{p}<0.004)$. The high-dose amlodipine/benazepril 10/40 mg/day combination resulted in reductions from baseline of MSSBP and MSDBP by 14.33 and $13.60 \mathrm{mmHg}$, respectively, in White patients $(\mathrm{p}<0.0001)$ and by 14.89 and $12.79 \mathrm{mmHg}$, respectively, in Black patients $(\mathrm{p}<0.0001)$. 


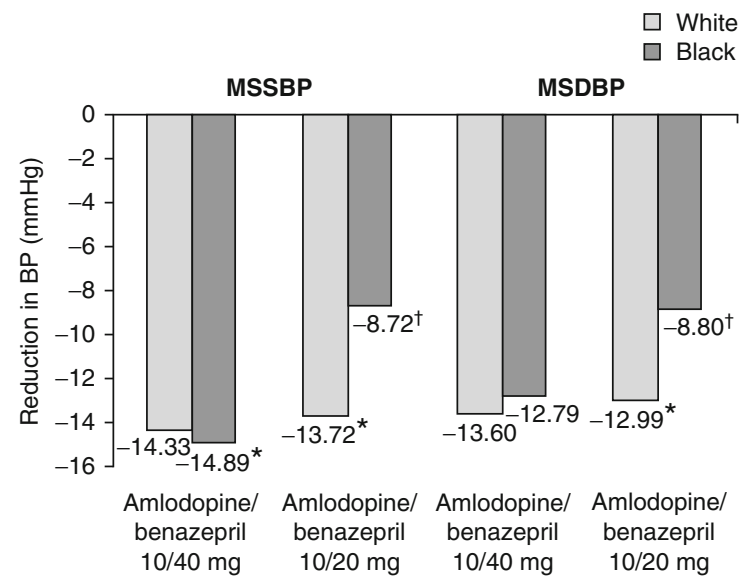

Fig. 2. The reductions in mean seated systolic blood pressure (MSSBP) and mean seated diastolic blood pressure (MSDBP) were significantly lower from baseline to endpoint for both White and Black patients treated with either amlodipine/benazepril 10/40 mg/day or amlodipine/benazepril 10/20 mg/day $(p<0.0001)$. The between-group comparisons showed a significant decrease in MSSBP and MSDBP in White patients compared with Black patients treated with low-dose amlodipine/benazepril 10/20 mg/day $(p<0.004)$; this racial difference was eliminated with high-dose amlodipine/benazepril $10 / 40 \mathrm{mg} /$ day $(p=0.388) .{ }^{*} p<0.0001$ compared with baseline; $+p<0.004$ between groups. $\mathbf{B P}=$ blood pressure.

In contrast with the low-dose amlodipine/ benazepril combination, there was no significant difference between the groups receiving the highdose combination $(\mathrm{p}<0.674)$. The effects of combination therapy on BP are depicted in figure 2 . The percentages of patients who achieved BP control $(\mathrm{BP}<140 / 90 \mathrm{mmHg})$ and the percentages of responders to treatment (MSDBP $<90 \mathrm{mmHg}$ or $\geq 10 \mathrm{mmHg}$ decrease from baseline) are listed in table II. In the high-dose combination treatment group, the control rate was identical in Black and White patients $(60.7 \%)$, whereas in the low-dose combination treatment group, the control rate was higher in White patients than in
Black patients $(61.2 \%$ vs $39.4 \%$; $p<0.0023)$. With respect to the responder rate, there was no difference between Black and White patients for the high-dose combination $(74.8 \%$ vs $77 \%$; $\mathrm{p}<0.639)$. In contrast, for the low-dose combination, the responder rate was lower in Black patients than in White patients $(50.7 \%$ vs $73.5 \%$; $<<0.007)$ [table II].

Most patients tolerated the treatment well, and there were no serious clinical or metabolic side effects noted, with the exception of pedal edema, which tended to be more common in the amlodipine monotherapy group (9.2\%) than in the amlodipine/ benazepril $10 / 20 \mathrm{mg}$ /day group $(5.5 \%)$ or in the

Table II. Blood pressure control and responder rates

\begin{tabular}{llll}
\hline Parameter & $\begin{array}{l}\text { Amlodipine/ } \\
\text { benazepril } \\
10 / 40 \mathrm{mg} \\
(\mathrm{n}[\%])\end{array}$ & $\mathrm{p}$-Value & $\begin{array}{c}\text { Amlodipine/ } \\
\text { benazepril } \\
10 / 20 \mathrm{mg} \\
(\mathrm{n}[\%])\end{array}$ \\
\hline Patients & 377 & 241 & $\begin{array}{c}\mathrm{p} \text {-Value } \\
\text { Control rate: blood pressure }<140 / 90 \mathrm{mmHg}\end{array}$ \\
$\quad$ White & $270[60.7]$ & 0.999 & $170[61.2]$ \\
Black & $107[60.7]$ & $71[39.4]$ & 0.002 \\
Responder rate: MSDBP $<90 \mathrm{mmHg}$ or $>10 \mathrm{mmHg}$ decrease & & 0.640 & $170[73.5]$ \\
$\quad$ White & $270[77.0]$ & & $71[50.7]$ \\
$\quad$ Black & $107[74.8]$ & & $<0.0007$ \\
\hline MSDBP $=$ mean seated diastolic blood pressure. & & & \\
\hline
\end{tabular}


amlodipine/benazepril 10/40 mg/day group (4.5\%), but the difference did not reach statistical significance. In total, 11 patients discontinued the studies because of pedal edema, two in the amlodipine/benazepril 10/20 $\mathrm{mg}$ group, two in the amlodipine/benazepril 10/40 mg group, and seven in the amlodipine monotherapy $10 \mathrm{mg} /$ day group. Cough was infrequent and occurred in fewer than $5 \%$ of the patients taking benazepril alone or in combination with amlodipine. Also, mild, nonsignificant increases in serum potassium, blood urea nitrogen (BUN), and creatinine levels were noted in some patients.

\section{Discussion and Conclusion}

Uncontrolled hypertension is a major risk factor for cardiovascular and stroke morbidity and mortality. In a meta-analysis of one million hypertensive patients, it was demonstrated that there was a linear relationship between the rise in systolic and diastolic BP from $115 / 75 \mathrm{mmHg}$ to $185 / 115$ $\mathrm{mmHg}$ and the incidence of cardiovascular complications and strokes for all ages. ${ }^{[19]}$ This analysis also showed that for each $20 \mathrm{mmHg}$ increase in systolic BP and each $10 \mathrm{mmHg}$ in diastolic BP, the risk of cardiovascular diseases and strokes doubles. Therefore, aggressive treatment of hypertension, with goals of $<140 / 90 \mathrm{mmHg}$ for uncomplicated hypertension and $<130 / 80 \mathrm{mmHg}$ for patients with diabetes mellitus, renal disease, or CHD, is recommended by the Seventh Report of the Joint National Committee on Prevention, Detection, Evaluation, and Treatment of High Blood Pressure (JNC-7), the European Society of Hypertension, the European Society of Cardiology, and the American Heart Association. ${ }^{[2-4]}$ Recently, more aggressive goals for BP reduction to $<135 / 85 \mathrm{mmHg}$ have been recommended by the International Society of Hypertension in Blacks. ${ }^{[13]}$ However, it is possible that future guidelines might relax these strict BP control recommendations because of conflicting evidence regarding their benefit. ${ }^{[20]}$

To accomplish these goals, it is often necessary to use multiple drug therapies. ${ }^{[2-6]} \mathrm{ACE}$ inhibitors and ARBs are drugs with proven cardioprotective, renoprotective, and cerebroprotective properties. ${ }^{[2]}$
However, certain populations, like AfricanAmericans, are resistant to drugs that block the renin-angiotensin-aldosterone system [RAAS], like ACE inhibitors and ARBs given as monotherapy, ${ }^{[22,23]}$ because these drugs exert their major antihypertensive effects through the blockade of RAAS, and Black patients are usually low-renin and volume-dependent hypertensive subjects. ${ }^{[2]}$

Several clinical trials have shown that the combination of ACE inhibitors with CCBs increases their hypotensive potency ${ }^{[11-17,25]}$ because of a synergistic effect of inhibition of RAAS and a direct arterial dilatory effect, which is independent of RAAS inhibition. Most of the previous publications have used lower-dose ACE inhibitor-CCB combinations and did not specifically focus on the antihypertensive effects of these drug combinations on Black hypertensive patients compared with their White counterparts.

In this report, we present our findings on lowdose amlodipine/benazepril 10/20 mg/day and high-dose amlodipine/benazepril 10/40 mg/day combination regimens for the treatment of Black and White hypertensive patients. Our results showed that the low-dose amlodipine/benazepril combination resulted in significantly greater BP reductions and higher $\mathrm{BP}$ control and responder rates in White compared with Black hypertensive patients. In contrast, the high-dose amlodipine/ benazepril combination eliminated this racial difference and resulted in similar reductions in BP control and responder rates. Other investigators have also reported that Black hypertensive patients treated with higher doses of ACE inhibitors show a greater BP response, compared with lower doses. ${ }^{[22,26-28]}$

Combinations of $\mathrm{CCBs}$ and $\mathrm{ACE}$ inhibitors or ARBs have complimentary mechanisms of action that provide augmented efficacy, with reductions not only in BP but also in cardiovascular morbidity and mortality. ${ }^{[29]}$ The combination of amlodipine with perindopril in ASCOT (the AngloScandinavian Cardiac Outcomes Trial) resulted in significant reductions in cardiovascular morbidity and mortality in high-risk hypertensive patients compared with an atenolol-diuretic combination, for similar reductions in BP. ${ }^{[30]}$ Also, in the ACCOMPLISH (Avoiding Cardiovascular Events 
through Combination Therapy in Patients Living with Systolic Hypertension) study, ${ }^{[31]}$ patients treated with a combination of benazepril with amlodipine had a lower incidence of cardiovascular events than patients treated with a combination of benazepril with hydrochlorothiazide.

A substudy of ASCOT, the CAFÉ (Conduit Artery Function Evaluation) study, showed that the reason for the superior performance of the amlodipine/lisinopril combination was the reduction in central aortic and pulse pressure compared with the atenolol/diuretic regimen. ${ }^{[32]}$ Central aortic pressure is more important than brachial pressure for target organ damage, and the patients who stand to benefit from this drug combination are older patients with decreased vascular compliance, diabetic patients, and patients with CHD and peripheral vascular disease. ${ }^{[33]}$ Peripheral edema is a common side effect of monotherapy with a dihydropyridine $\mathrm{CCB}$ because of arteriolar dilation leading to increased capillary pressure, which increases the arteriolar-venous capillary gradient with fluid exudation and edema. This hemodynamic imbalance is ameliorated with the addition of ACE inhibitors or ARBs, which cause both arteriolar and venous dilation, enabling the venous system to absorb the excess tissue fluid. ${ }^{[1,12,34,35]}$

In our studies, the incidence of pedal edema tended to be higher with amlodipine monotherapy $(9.2 \%)$ and improved with the addition of high-dose benazepril (4.5\%). Overall, the drugs were well tolerated, and only minor clinical and metabolic side effects occurred, not necessitating patient discontinuation from the studies. Only a few patients were discontinued because of pedal edema, and most were in the amlodipine monotherapy group.

\section{Acknowledgments}

The author received research grants from Novartis for the conduct of the studies. He declares no other conflicts of interest.

\section{References}

1. Egan BM, Zhao Y, Axon BN. US trends in prevalence, awareness, treatment and control of hypertension, 19882008. JAMA 2010; 303: 2043-50
2. Chobanian AV, Bakris GL, Black HR, et al. Seventh report of the Joint National Committee on Prevention, Detection, Evaluation and Treatment of High Blood Pressure. Hypertension 2003; 42: 1206-52

3. Mancia G, De Baker G, Dominiczak A, et al. 2007 ESHESC practice guidelines for management of arterial hypertension: ESH-ESC Task Force on the Management of Arterial Hypertension. J Hypertens 2007; 25: 751-62

4. Rosendorff C, Black HR, Cannon CP, et al. Treatment of hypertension in the prevention and management of ischemic heart disease: a scientific statement from the American Heart Association Council for High Blood Pressure Research and the Councils of Clinical Cardiology and Epidemiology and Prevention. Circulation 2007; 115: 2761-88

5. Oparil S, Chrysant SG, Melino M, et al. Long-term efficacy of a combination of amlodipine and olmesartan medoxomil \pm hydrochlotothiazide in patients with hypertension stratified by age, race, and diabetes status: a substudy of the COACH trial. J Hum Hypertens 2010; 24: 831-8

6. Cushman WC, Ford CE, Cutler JA, et al. Success and predictors of blood pressure control in diverse North American settings: the Antihypertensive and Lipid Lowering Treatment to Prevent Heart Attack Trial (ALLHAT). J Clin Hypertens 2002; 4: 393-404

7. Hilleman DE, Ryschon KL, Mohiuddin SM, et al. Fixeddose combination vs monotherapy in hypertension: a metaanalysis. J Hum Hypertens 1999; 13: 477-83

8. Adler AI, Stratton IM, Neil HA, et al. Association of systolic blood pressure with macrovascular and microvascular complications in type 2 diabetes (UKPDS 36): prospective observational study. BMJ 2000; 321: 412-9

9. Lazarus JM, Bourgoignie JJ, Buckalew VM, et al. Achievement of safety of low blood pressure goal in chronic renal disease. The Modification of Diet in Renal Disease Study Group. Hypertension 1997; 29: 641-50

10. Hansson L, Zanchetti A, Carruthers SG, et al. Effects of intensive blood pressure lowering and low-dose aspirin in patients with hypertension: principal results of the Hypertension Optimal Treatment (HOT) randomized trial. HOT Study Group. Lancet 1998; 351: 1755-62

11. Frishman WH, Ram CV, McMahon FD, et al. Comparison of amlodipine and benazepril monotherapy to amlodipine plus benazepril in patients with systemic hypertension: a randomized, double-blind, placebo-controlled, parallel group study. The Benazepril/Amlodipine Study Group. J Clin Pharmacol 1995; 35: 1060-6

12. Gradman AH, Cutler NR, Davis PJ, et al. Combined enalapril and felodipine extended release (ER). Systemic Hypertension Enalapril-Felodipine ER Factorial Study Group. Am J Cardiol 1997; 79: 431-5

13. Flack JM, Sica DA, Bakris GL, et al. Management of high blood pressure in Blacks: an update of the International Society of Hypertension in Blacks consensus statement. Hypertension 2010; 56: 780-800

14. Chrysant SG, Gavras H, Niederman AL, et al. Clinical utility of long-term enalapril/diltiazem ER in stage 3-4 essential hypertension. Long-Term Use of Enalapril/Diltiazem ER in Stage 3-4 Hypertension Group. J Clin Pharmacol 1997; 37: 810-5

15. Jamerson KA, Nwose O, Jean-Louise $\mathrm{L}$, et al. Initial angiotensin-converting enzyme inhibitor/calcium channel 
blocking combination therapy achieves superior blood pressure control compared with calcium channel blocker monotherapy in patients with stage 2 hypertension. Am J Hypertens 2004; 17: 495-501

16. Messerli FH, Weir MR, Neutel JM. Combination therapy of amlodipine/benazepril versus monotherapy with amlodipine in a practice-based setting. Am J Hypertens 2002; 15: 550-6

17. Chrysant SG, Bakris GL. Amlodipine/benazepril combination therapy for hypertensive patients nonresponsive to benazepril monotherapy. Am J Hypertens 2004; 17: 590-6

18. Chrysant SG, Melino M, Karki S, et al. The combination of olmesartan medoxomil and amlodipine besylate in controlling high blood pressure: $\mathrm{COACH}$, a randomized, double-blind, placebo-controlled, 8 week factorial efficacy and safety study. Clin Ther 2008; 30: 587-604

19. Lewington S, Clarke R, Orizilbash W, et al. Age-specific relevance of usual blood pressure to vascular mortality: a meta-analysis of individual data for one million adults in 61 prospective studies. Lancet 2002; 360: 1903-13

20. Chrysant SG, Chrysant GS. Current status of aggressive blood glucose and blood pressure control in diabetic hypertensive subjects. Am J Cardiol 2011; 107: 1856-61

21. Chrysant SG, Chrysant GS. The pleiotropic effects of angiotensin receptor blockers. J Clin Hypertens 2006; 8: 261-8

22. Cohn JN, Julius S, Neutel J, et al. Clinical experience with perindopril in African-American hypertensive patients: a large United States community trial. Am J Hypertens 2004; 17: $134-8$

23. Bakris GL, Smith DH, Giles TD, et al. Comparative antihypertensive efficacy of angiotensin receptor blocker-based treatment in African-American and White patients. J Clin Hypertens 2005; 7: 587-95

24. Chrysant SG, Danisa K, Kem DC, et al. Racial differences in pressure, volume and renin interrelationships in essential hypertension. Hypertension 1979; 1: 136-41

25. Dequatro V, Lee D. Fixed-dose combination therapy with trandolapril and verapamil SR is effective in primary hypertension. Trandolapril Study Group. Am J Hypertens 1997; 10: 138S-145S

26. Saunders E, Gavin III JR. Blockade of the renin angiotensin system in African-Americans with hypertension and cardiovascular disease. J Clin Hypertens 2003; 5: 12-7
27. Flack JM, Mensah GA, Ferrario CM. Using angiotensin converting enzyme inhibitors in African-American hypertensives: a new approach to treating hypertension and preventing target organ damage. Curr Med Res Opin 2000; 16: $66-79$

28. Douglas JG, Bakris GL, Epstein M, et al. Management of high blood pressure in African Americans: consensus statement of the Hypertension in African Americans Working Group of the International Society on Hypertension in Blacks. Arch Intern Med 2003; 163: 525-41

29. Chrysant SG. Using fixed-dose combination therapies to achieve blood pressure goals. Clin Drug Investig 2008; 28: 713-34

30. Dahlof B, Sever PS, Poulter NR, et al. Prevention of cardiovascular events with an antihypertensive regimen of amlodipine adding perindopril as required versus atenolol adding bendroflumethiazide as required, in the AngloScandinavian Cardiac Outcomes Trial Blood Pressure Lowering Arm (ASCOT-BPLA): a multicenter randomized controlled trial. Lancet 2005; 366: 895-906

31. Jamerson K, Weber MA, Bakris GL, et al. Benazepril plus amlodipine or hydrochlorothiazide for hypertension in high risk patients. N Engl J Med 2008; 359: 2417-28

32. Williams B, Lacy PS, Thom SM, et al. Differential impact of blood pressure-lowering drugs on central aortic pressure and clinical outcomes: principal results of the Conduit Artery Function Evaluation (CAFÉ) study. Circulation 2006; 113: 1213-25

33. Roman MJ, Devereux RB, Kizer JR, et al. Central pressure more strongly relates to vascular disease and outcome than does brachial pressure: the Strong Heart Study. Hypertension 2007; 50: 197-203

34. Sica DA. Calcium channel blocker-related peripheral edema: can it be resolved? J Clin Hypertens 2003; 5: 291-4

35. Chrysant SG. Proactive compared with passive adverse event recognition: calcium channel blocker-associated edema. J Clin Hypertens 2008; 10: 716-22

Correspondence: Dr. Steven G. Chrysant, 5850 W. Wilshire Blvd., Oklahoma City, OK 73132-4904, USA.

E-mail: schrysant@yahoo.com 